\title{
DEVELOPMENT AND TESTING OF A FRICTION-BASED POST-INSTALLABLE FIBER-OPTIC MONITORING SYSTEM FOR SUBSEA APPLICATIONS
}

\author{
Nicole L. Bentley \\ NASA-Johnson Space Center \\ Houston, TX, USA \\ David V. Brower \\ Astro Technology Inc. \\ Houston, TX, USA \\ Suy Q. Le \\ NASA-Johnson Space Center \\ Houston, TX, USA
}

\author{
Calvin H. Seaman \\ Astro Technology Inc. \\ Houston, TX, USA \\ Henry $\mathrm{H}$. Tang \\ Aerodyne Industries, LLC \\ Houston, TX, USA
}

\begin{abstract}
This paper presents the design and development of a friction-based coupling device for a fiber-optic monitoring system capable of measuring pressure, strain, and temperature that can be deployed on existing subsea structures. A summary is provided of the design concept, prototype development, prototype performance testing, and subsequent design refinements of the device. The results of laboratory testing of the first prototype performed at the National Aeronautics and Space Administration (NASA) Johnson Space Center (JSC) are also included. Limitations of the initial concept were identified during testing and future design improvements were proposed and later implemented. These new features enhance the coupling of the sensor device and improve the monitoring system measurement capabilities.
\end{abstract}

A major challenge of a post-installed instrumentation monitoring system is to ensure adequate coupling between the instruments and the structure of interest for reliable measurements. Friction-based devices have the potential to overcome coupling limitations caused by marine growth and soil contamination on flowlines, risers, and other subsea structures. The work described in this paper investigates the design and test of a friction-based coupling device (herein referred to as a friction clamp) which is suitable for pipelines and structures that are suspended in the water column as well as for those that are resting on the seabed. The monitoring elements consist of fiberoptic sensors that are bonded to a stainless steel clamshell assembly with a high-friction surface coating. The friction clamp incorporates a single hinge design to facilitate installation of the clamp and dual rows of opposing fasteners to distribute the clamping force along the structure. The friction clamp can be modified to be installed by commercial divers in shallow depths or by remotely operated vehicles in deep-water applications. NASA-JSC was involved in the selection and testing of the friction coating, and in the design and testing of the prototype clamp device. Four-inch diameter and eight-inch diameter sub-scale friction clamp prototypes were built and tested to evaluate the strain measuring capabilities of the design under different loading scenarios. The testing revealed some limitations of the initial design concept, and subsequent refinements were explored to improve the measurement performance of the system.

This study was part of a collaboration between NASA-JSC and Astro Technology Inc. within a study called Clear Gulf. The primary objective of the Clear Gulf study is to develop advanced instrumentation technologies that will improve operational safety and reduce the risk of hydrocarbon spillage. NASA provided unique insights, expansive test facilities, and technical expertise to advance technologies that will benefit the environment, the public, and commercial industries.

\section{INTRODUCTION}

In the OMAE2015-41305 paper, "Development and Testing of a Post-Installable Deepwater Monitoring System Using Fiber-

This material is declared a work of the U.S. Government and is not subject to copyright protection in the United States. Approved for public release; distribution is unlimited. 
Optic Sensors", the development of an adhesive-based postinstallable fiber-optic monitoring system was discussed [1]. The fiber-optic monitoring system was designed to measure and monitor vital signals such as strain, stress, and temperature of a structure. The adhesive-based system was developed and successfully deployed on several offshore tension leg platforms in shallow water applications [2]. In addition to the adhesive-based system, a friction-based system was also under development. The friction-based system is intended to be used for both shallow- and deep-water structural health monitoring applications, where postdeployment installation of the adhesive-based system is not feasible. The friction-based system is designed for installation on subsea structures such as pipelines, risers, wellheads, and other offshore platform infrastructure. Compared to the adhesive-based system, the friction-based system is much less sensitive to the presence of marine growth and other contamination sources, and can easily be installed along the seabed.

Compared to existing monitoring systems, such as strap-on accelerometer or load cell systems, the fiber-optic sensor systems have the following advantages:

- The signal is immune from electrical interference and is suitable for long distance deployment (e.g. 60 to 100 miles).

- The fiber-optic sensors are very sensitive and can be used to measure pressure, vibration, and temperature in addition to stress and strain.

- The systems do not require dynamic movement of the structure for measurement.

- The systems were specifically designed to be postinstallable on existing subsea structure (e.g. risers, flowlines, tendons, etc.)

This paper documents the continuing development process of the friction-based system, and the process is illustrated in Figure 1. Two engineering design iterations, referred to as Mark I and Mark II were completed and discussed in this paper. The detailed development and testing of the Mark I are described. The various challenges and lessons learned during its development are presented here. The Mark II design improvements and the preliminary findings from the Mark II prototype testing are also briefly discussed.

The development process began with the proposal of a friction-based clamp mechanism concept. A study was initiated to evaluate the feasibility of the concept. The feasibility phase focused on the technical challenge of achieving adequate sensor coupling with a structure and on the evaluation of various friction-enhancing surface treatments. After the feasibility evaluation, the first conceptual design (Mark I) was formulated. Proof-of-concept tests were conducted to assess the effectiveness of the friction coupling mechanism and the quality of the measured signals. All testing was performed in ambient indoor conditions or outdoors in open air. The Mark I proof-of-concept phase involved the building and testing of 4-inch and 8-inch diameter sub-scale prototypes, which were installed onto steel pipes for testing. The Mark I prototypes were tested in tension, compression, and bending to evaluate their ability to measure strain generated by mechanical loading. Based on the results and findings from the Mark I sub-scale prototype testing, the design was reevaluated and several improvements were incorporated into the Mark II design. The Mark II proof-of-concept testing involved evaluating a 24 -inch diameter full-scale prototype. The details of these development process phases are presented in the following sections of this paper.

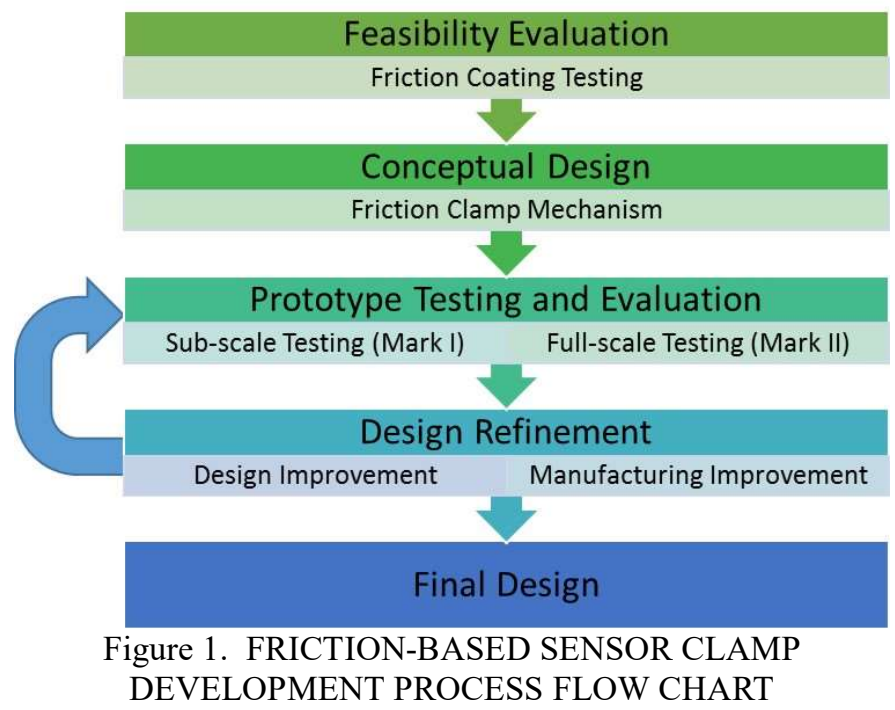

The work described in this paper is the result of a collaboration between the National Aeronautics and Space Administration (NASA) Johnson Space Center (JSC) and Astro Technology Incorporated (ATI) [3]. The collaboration was carried out under a Space Act Agreement (SAA) between NASA-JSC and ATI. The SAA allows commercial industries to leverage unique NASA resources and expertise to develop new technologies that can benefit both the U.S. Government Space Program and commercial industries.

\section{FRICTION CLAMP CONCEPTS}

A post-installable fiber-optic structural health monitoring system concept was proposed by ATI. The fiber-optic sensor system can measure and record temperature, stress, and strain data in real-time for offshore subsea applications. The system provides vital information for operators to monitor structural and hardware integrity as well as to enhance operations and safety. The monitoring system can be installed before or after the structure or hardware has been deployed in the field. The sensors can be custom tailored for installation onto varying surfaces of land-based or subsea structures. ATI defined the functions and attributes of the monitoring system, as outlined below. ATI collaborated with NASA-JSC to jointly develop the friction-

This material is declared a work of the U.S. Government and is not subject to copyright protection in the United States. Approved for public release; distribution is unlimited. 
based coupling mechanism for the fiber-optic sensor system to provide the following functions:

- It can be installed onto a structure underwater postdeployment.

- It can be installed by a commercial diver or a remotely operated vehicle.

- It can be installed, operated, and survive in both deep water and seabed environments.

- It has a robust and reliable coupling mechanism.

- It provides accurate and reliable sensing and data transmission in real-time.

- It is corrosion resistant.

- The installation and operation is insensitive to environmental contamination.

\section{FEASIBILITY EVALUATION}

Before the first design concept was formulated, a feasibility study was conducted at NASA-JSC to assess whether the critical function of the friction clamp design could successfully be achieved. The objective of the feasibility study was to identify a metal surface treatment that would eliminate slippage between the sensor clamp and the coupling structure. Reliable coupling (i.e. non-slip) between the clamp and structure is vital for accurate sensing. Therefore, a robust and effective coupling surface with a high coefficient of friction is required to maintain reliable coupling of the friction clamp sensor elements with the structure of interest. The treated surface should also be corrosion resistant to typical offshore deep-sea environments.

Various finishes and coatings for stainless-steel surfaces were researched, and several were selected for test and evaluation at NASA-JSC. The various surface treatments were chosen based on their favorable friction and corrosion resistance properties. The first series of tests evaluated several friction agents and surface finishes. These friction agents were made at NASA-JSC from a combination of abrasive particles and binders. The second series of tests evaluated 4 grades of proprietary, commercially available, carbide coatings.

Non-standard shear friction tests were performed to evaluate the shear strength of the differently treated surfaces against a bare steel bar. Each friction test assembly consisted of 2 slotted tension plates, with differently treated opposing surfaces, clamped together by two joint plates with bolts, washers, and nuts. A photograph of the friction test assembly is shown in Figure 2. Each joint plate surface was treated with a candidate friction finish or coating, representing the clamping surface. The metal surface on the tension plate, representing the structural surface, had no surface treatment. The bolts of the assembly were torqued to 30 in-lbs. (3.39 n-m), and the assembly was pull tested with a universal testing machine. The peak shear load, which occurred at the start of slippage, was measured and recorded. A photograph of the shear friction test setup is shown in Figure 3.

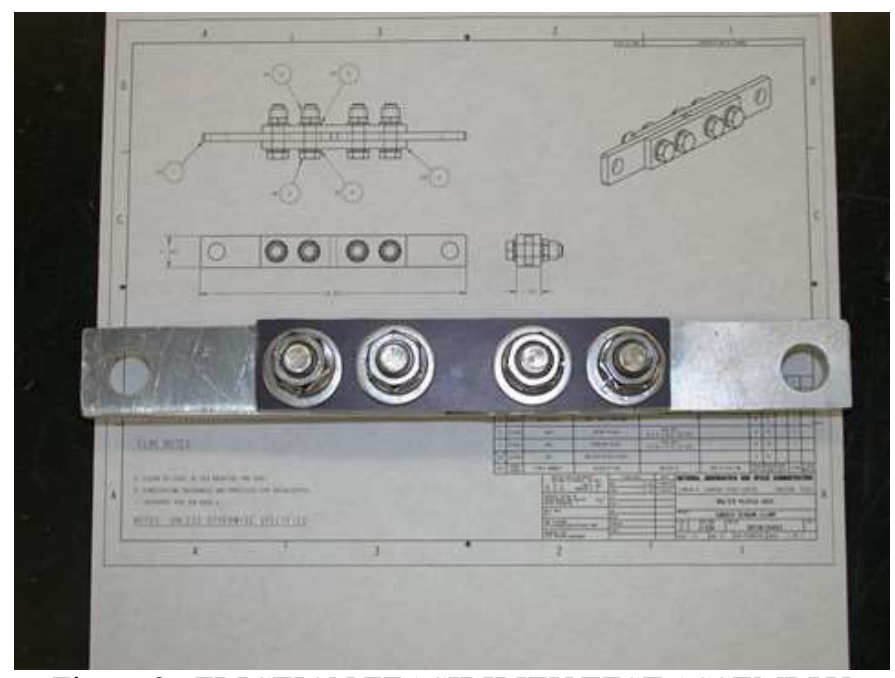

Figure 2. FRICTION FEASIBILITY TEST ASSEMBLY

The friction agents used in the first series of tests included the following mixture of binders and abrasives: Acrylic, epoxy, epoxy primer, aluminum oxide, silicon carbide (FEPA 60 \& 100) and boron carbide (FEPA 60 \& 100). Under high compressive load from the clamping, the abrasives would embed themselves into the underlying metal of the faying surfaces, thereby creating strong anchors across the two mating pieces. The abrasives, with their high strength and hardness, would bear the brunt of the shear and prevent slippage. The binder served as a medium for application and provided a layer of corrosion protection.

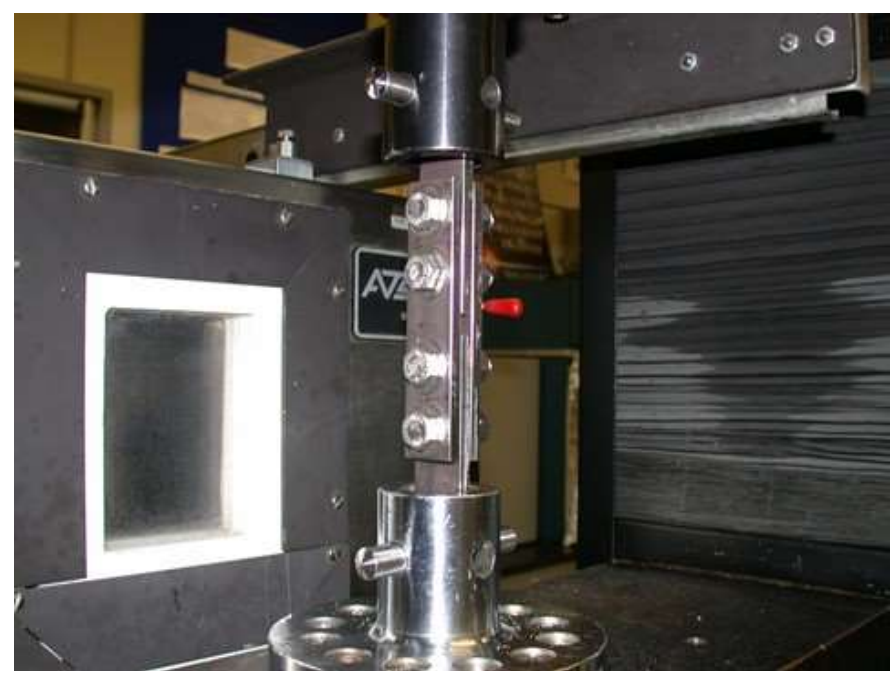

Figure 3. SHEAR STRENGTH TEST SETUP

The shear friction test results of the first series of friction agents are shown in Table. 1. For comparison, tests were also performed on a bolted assembly without any surface treatment, and on a sample with a knurled surface. The results indicated

This material is declared a work of the U.S. Government and is not subject to copyright protection in the United States. Approved for public release; distribution is unlimited. 
that the bare metal test article, without any surface treatment whatsoever, provided the most friction. None of the friction coatings, or the knurled finish, provided any improvement over the bare metal surface. The poor performance of the friction agents may be attributed to the failure of achieving a cohesive and uniform abrasive coating on the metal surface. It was observed that the abrasives were not well-dispersed and tended to clump together during application. As a result, the abrasives ended up rubbing against themselves rather than embedding into the faying metal surface.

Table 1. FIRST SERIES OF SHEAR FRICTION COATING TEST RESULTS

\begin{tabular}{|l|c|}
\hline \multicolumn{1}{|c|}{ Surface Treatment } & $\begin{array}{c}\text { Peak Load } \\
\text { (lbf) }\end{array}$ \\
\hline None, Bare Metal Surface & 2496 \\
\hline Knurled (sharp diamond pattern 0.05 inch deep) & 2057 \\
\hline $\begin{array}{l}\text { Mil Spec Standard Epoxy Coating w/ Aluminum } \\
\text { Oxide }\end{array}$ & 1738 \\
\hline Epoxy Primer w/ Aluminum Oxide & 1315 \\
\hline Black Silicon Carbide 60 w/ Epoxy Primer & 1537 \\
\hline Black Silicon Carbide 100 w/ Epoxy Primer & 1622 \\
\hline Boron Carbide 60 w/ Epoxy Primer & 1247 \\
\hline Boron Carbide 100 w/ Epoxy Primer & 1267 \\
\hline
\end{tabular}

For the second series of shear friction tests, four grades of carbide coatings were evaluated. The carbide coatings have high resistance to wear and corrosion and are metallurgically bonded through an electrofusion process. Grades 1 to 3 of the coatings contain tungsten carbide grits. Grade 4 contains stellite grits, which are made of a cobalt-chromium alloy. The build-up thickness of each grade ranges from $0.0025 \mathrm{inch}(0.0635 \mathrm{~mm})$ to $0.017 \mathrm{inch}(0.4318 \mathrm{~mm})$. The test plate assemblies were sent to the manufacturer to apply the proprietary coatings.

The test results for the carbide coatings are shown in Table 2. The results show that the carbide coatings provide a 12$46 \%$ improvement over the bare metal finish. Post-test analysis of the tension plate surfaces indicated that the grits were uniformly embedded into the faying metal surface, which resulted in a strong grip. The abrasive engagement was deep and uniform throughout the metal surface of the tension plate. The grade 4 coating achieved the highest friction rating and was selected for the friction clamp design and prototyping.
Table 2. SECOND SERIES OF SHEAR FRICTION COATING TEST RESULTS

\begin{tabular}{|c|c|c|c|}
\hline $\begin{array}{c}\text { Carbide } \\
\text { Coating }\end{array}$ & $\begin{array}{c}\text { Build- } \\
\text { up } \\
\text { (in) }\end{array}$ & $\begin{array}{c}\text { Peak } \\
\text { Load } \\
\text { (lbf) }\end{array}$ & $\begin{array}{c}\text { Shear Strength Increase } \\
\text { Compare to Bare Metal } \\
\text { Surface }\end{array}$ \\
\hline None & 0 & 2496 & N/A \\
\hline Grade \#1 & 0.0025 & 2807 & $12 \%$ \\
\hline Grade \#2 & 0.006 & 2808 & $12 \%$ \\
\hline Grade \#3 & 0.011 & 3120 & $25 \%$ \\
\hline Grade \#4 & 0.017 & 3665 & $46 \%$ \\
\hline
\end{tabular}

\section{MARK I DESIGN AND PROTOTYPE}

The friction clamp allows fiber-optic sensors to be mounted on subsea structures for the monitoring of strain and temperature. The Mark I friction clamp incorporated a clamshell design which consisted of two corrosion-resistant steel semicircular halves with hinges on one side and bolt flanges on both sides. Fiberoptic sensors were bonded at various locations on the outside surfaces of the clamp to detect strain and temperature. The carbide surface coating was applied on the inside surface of the clamp. Once the friction clamp was aligned and mounted on the structure being monitored, bolts on both sides were tightened to ensure that the clamp halves were fastened with sufficient clamping force to achieve a secure grip with no slippage. The coupling of the clamp to the structure allows strains on the structure to be transferred to and detected by the sensors on the clamp body. The signals were routed through cabling and sent to a data acquisition system for collection and monitoring. A drawing of the Mark I friction clamp design is shown in Figure 4.

In order to evaluate the Mark I design, sub-scale prototypes were built and tested. One friction clamp prototype with a 4-inch $(10.16 \mathrm{~cm})$ diameter and two friction clamp prototypes with an 8 -inch $(20.32 \mathrm{~cm})$ diameter were fabricated. A photograph of an 8-inch friction clamp prototype is shown in Figure 5. The friction clamp prototype clamshells were fabricated by NASAJSC, and the Fiber Bragg Grating sensors with strain sensitivity of approximately $1.2 \mathrm{pm} / \mu \varepsilon$ were installed onto the clamshells by ATI. Each friction clamp prototype has 4 axial fiber-optic sensors and 1 diagonal fiber-optic sensor. The four axial sensors are positioned 90 degrees apart along the circumference of the clamshell. The axial sensors measure the tensile and compressive strains, and the diagonal sensor measures the bias strain.

This material is declared a work of the U.S. Government and is not subject to copyright protection in the United States. Approved for public release; distribution is unlimited. 


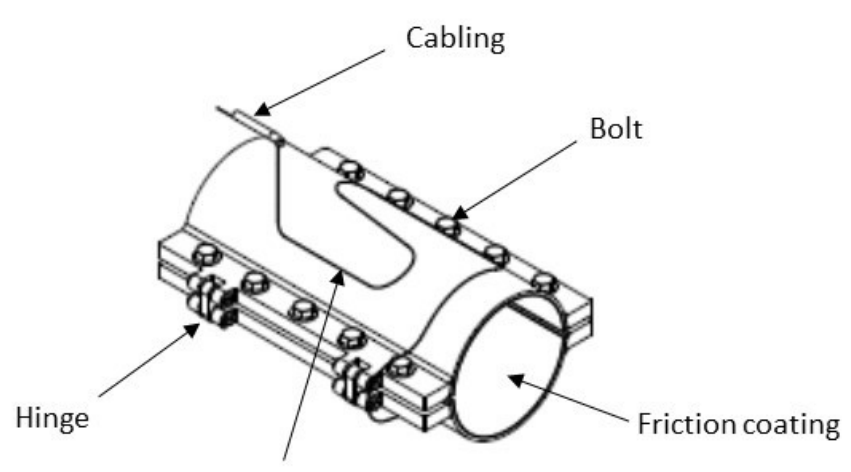

Fiber optic sensors

Figure 4. MARK I FRICTION CLAMP DESIGN

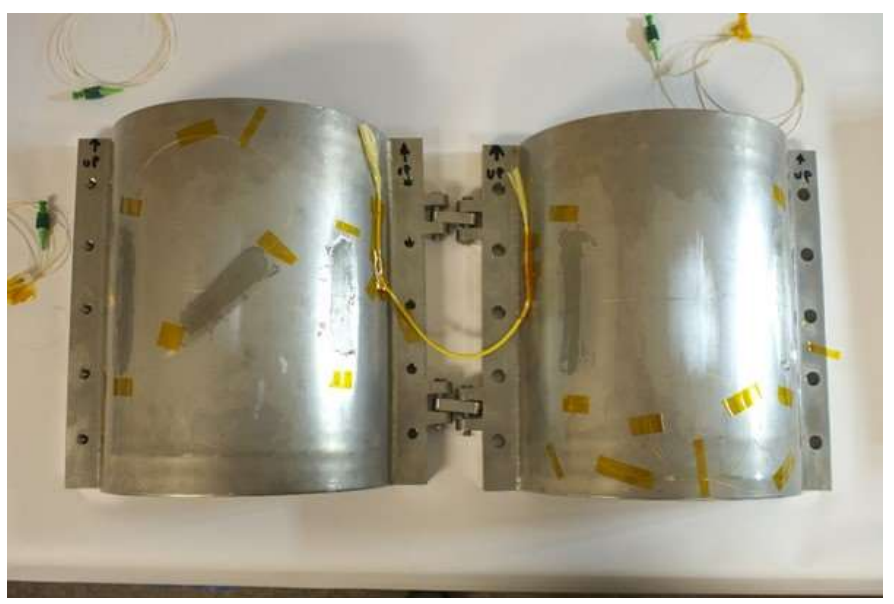

Figure 5. 8-INCH FRICTION CLAMP PROTOTYPE

\section{MARK I DESIGN SUB-SCALE PROTOTYPE TESTING}

A series of mechanical tension, compression, and bending tests were conducted at NASA-JSC to evaluate the performance of the friction clamp prototypes. These tests were designed to evaluate the strain measuring capabilities in an assembly configuration that is comparable to a realistic oil and gas industry application. The relative accuracy of the strain measurements was used to infer the effectiveness of the prototype attachment mechanism and the reliability of the sensing system.

The friction clamp prototype was installed onto a steel test pipe, which simulated a pipeline structure, to form a test assembly for evaluation. A fiber-optic temperature sensor was also attached to the surface of each test pipe. Since temperature affects the refractive index of glass fiber, the temperature sensor data was used to compensate for any thermal effect on the strain measurements. Two different diameter steel pipes, generally described as 4-inch and 8-inch, were used. They are similar to the API 5L PSL-2 X52 grade pipe. The 4-inch pipe was an NPS 4 Schedule 40 pipe and the 8 -inch pipe was an NPS 8 Schedule
10 pipe. The prototype friction clamps were installed onto the test pipes with the as-received surface condition in an ambient environment.

One 4-inch friction clamp prototype and one 8-inch friction clamp prototype were used for tension/compression testing. The other 8-inch friction clamp prototype was used for 4-point bending tests. The 4 -inch friction clamp bolts were torqued to 5 ft.-lbf $(6.78 \mathrm{n}-\mathrm{m})$ and the 8 -inch friction clamps bolts were torqued to $10 \mathrm{ft}$-lbf (13.56 n-m). Additional torque was applied during tension/compression testing to assess the effect of bolt torque on clamp grip strength and on the fiber-optic sensor strain measurements. After clamp installation, conventional resistance strain gauges were also installed on the test pipes to complete the test assemblies. Each test assembly was subjected to various loading scenarios, and the strain measurements from the fiberoptic sensors and the resistance strain gauges were recorded and analyzed. The accuracy and performance of the prototype's fiber-optic sensor system were evaluated by comparing the measurements to data from the resistance strain gauges. The 4inch friction clamp test article is shown in Figure 6.

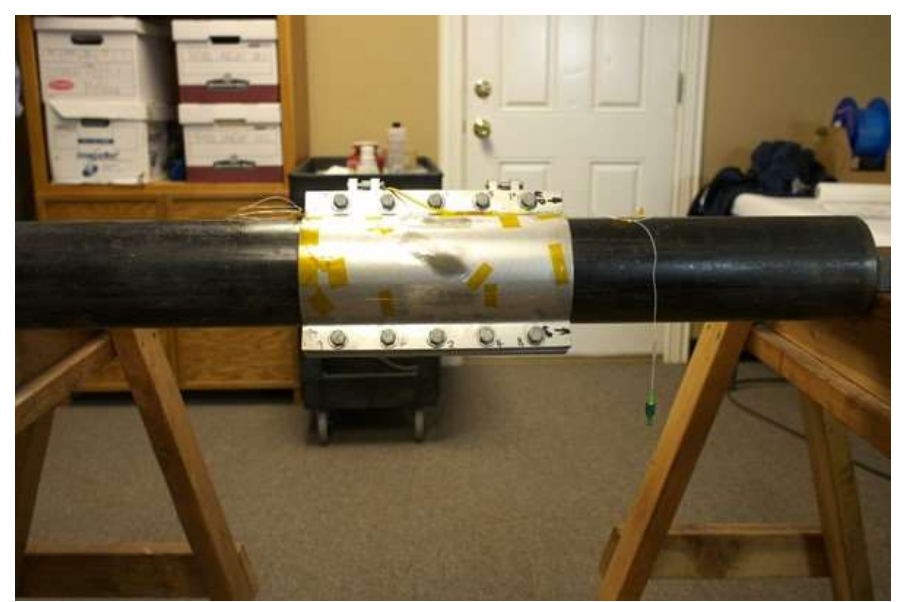

Figure 6. TEST ASSEMBLY WITH 4-INCH FRICTION CLAMP PROTOTYPE

The tension and compression tests were performed using a hydraulic load frame with a maximum load capacity of 224,800 $\operatorname{lbf}(1,000 \mathrm{kN})$. The test assemblies were evaluated at two test speeds, low speed, $0.1 \mathrm{in} / \mathrm{min}(0.25 \mathrm{~cm} / \mathrm{min})$, and high speed, 0.5 in $/ \mathrm{min}(1.27 \mathrm{~cm} / \mathrm{min})$. An optical sensing interrogator with a wavelength accuracy of $1 \mathrm{pm}$, dynamic range of $50 \mathrm{db}$, and scan frequency of $2 \mathrm{~Hz}$ was used to acquire the fiber-optic sensor data. The fiber optic system has accuracy and resolution of less than one micro-strain. A separate system with a $10 \mathrm{~Hz}$ data acquisition rate was used to record the resistance strain gauge data. Each test was conducted by loading the test assembly to up to $\pm 110,000 \mathrm{lbf}(490 \mathrm{kN})$ with approximately $\pm 1250 \mu \mathrm{in} / \mu$ in strain, which is below the yield strength of the test pipes. The test assembly was held at peak load for up to 180 seconds to observe any measurement abnormalities. The test was repeated up to 10 test cycles to observe the repeatability of the measurements.

This material is declared a work of the U.S. Government and is not subject to copyright protection in the United States. Approved for public release; distribution is unlimited. 
Photographs of the tension/compression test setup are shown in Figure 7. The tension/compression test matrix is shown in Table 3.

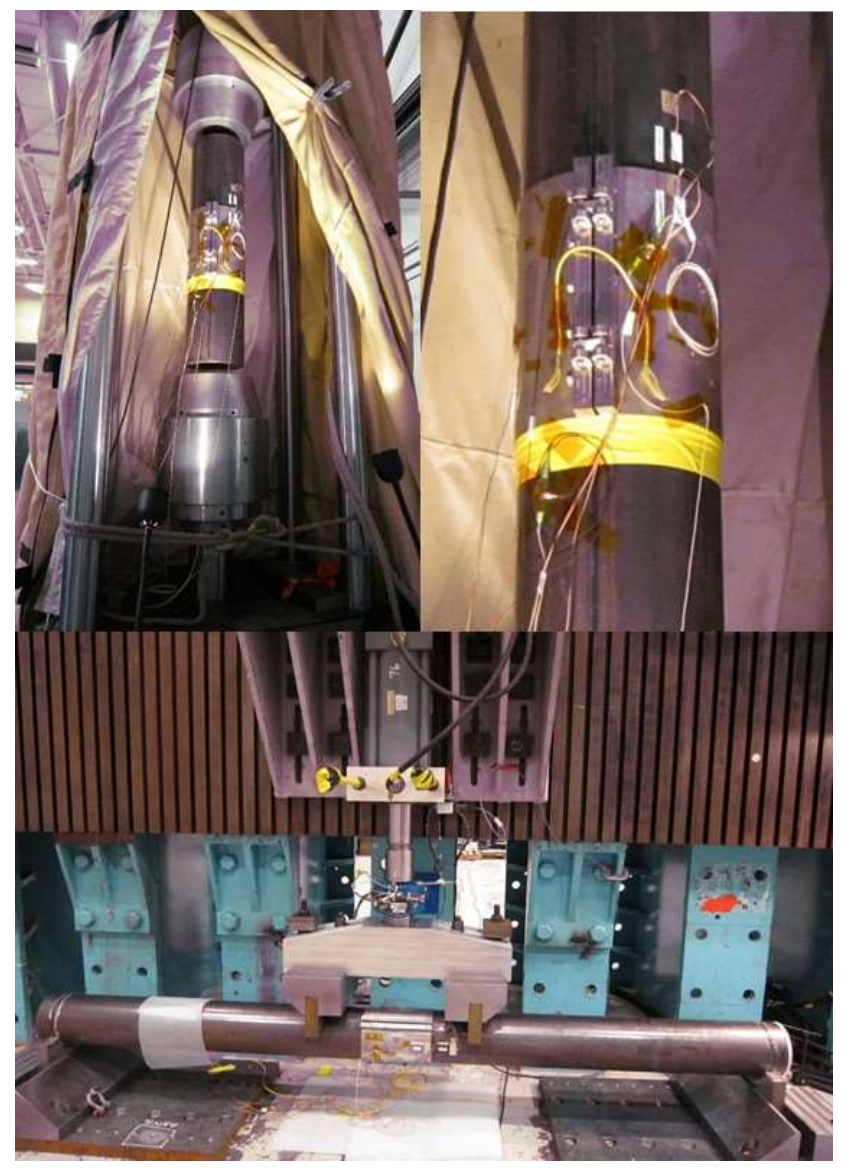

Figure 7. TENSION/COMPRESSION AND 4-POINT BENDING TEST SETUP

Table 3. FRICTION CLAMP TENSION/COMPRESSION TEST MATRIX

\begin{tabular}{|c|c|c|c|c|c|}
\hline $\begin{array}{c}\text { Test } \\
\text { Number }\end{array}$ & Test Articles & Test Configuration & $\begin{array}{l}\text { Test } \\
\text { Speed }\end{array}$ & $\begin{array}{c}\text { Hold } \\
\text { Time } \\
\text { (seconds) }\end{array}$ & $\begin{array}{c}\text { No. of } \\
\text { Repeat / } \\
\text { Cycle }\end{array}$ \\
\hline TC-1-2 & \multirow{3}{*}{$\begin{array}{c}4.5 " \text { OD x } 0.237 " \text { Wall x } \\
\text { 36" Length Pipes (Test } \\
\text { Article \# 1) }\end{array}$} & \multirow{6}{*}{ Baseline (No Clamp) } & Slow & 180 & 10 \\
\hline TC-1-3 & & & High & 180 & 10 \\
\hline TC-1-4 & & & N/A & N/A & N/A \\
\hline TC-1-6 & \multirow{3}{*}{$\begin{array}{c}\text { 8.625" OD x } 0.148 " \text { Wall } \\
\text { x 36" Length Pipe (Test } \\
\text { Article \# 4) }\end{array}$} & & Slow & 180 & 10 \\
\hline TC-1-7 & & & High & 180 & 10 \\
\hline TC-1-11 & & & N/A & N/A & N/A \\
\hline TC-2-3 & \multirow{4}{*}{$\begin{array}{c}\text { 4.5" OD x 0.237" Wall x } \\
\text { 36" Length Pipes (Test } \\
\text { Article \# 2) }\end{array}$} & \multirow{2}{*}{$\begin{array}{c}\text { Friction Clamp with } 5 \\
\text { ft.lb Bolt Torque } \\
\end{array}$} & Slow & 180 & 10 \\
\hline TC-2-4 & & & High & 180 & 10 \\
\hline TC-2-5 & & $\begin{array}{c}\text { Friction Clamp with } 7 \\
\mathrm{ft} . \mathrm{lb} \text { Bolt Torque }\end{array}$ & Slow & 180 & 3 \\
\hline TC-2-6 & & $\begin{array}{l}\text { Friction Clamp with } \\
10 \mathrm{ft} \text {.lb Bolt Torque }\end{array}$ & Slow & 90 & 5 \\
\hline TC-2-8 & \multirow{6}{*}{$\begin{array}{c}\text { 8.625" OD x } 0.148 " \text { Wall } \\
\text { x 36" Length Pipe (Test } \\
\text { Article \#5a) }\end{array}$} & \multirow{2}{*}{$\begin{array}{l}\text { Friction Clamp with } \\
10 \mathrm{ft} . \mathrm{lb} \text { Bolt Torque }\end{array}$} & Slow & 90 & 5 \\
\hline TC-2-9 & & & Slow & 90 & 5 \\
\hline TC-2-10 & & \multirow{2}{*}{$\begin{array}{l}\text { Friction Clamp with } \\
13 \mathrm{ft} . \mathrm{Ib} \text { Bolt Torque }\end{array}$} & Slow & 90 & 5 \\
\hline TC-2-11 & & & Slow & 90 & 5 \\
\hline TC-2-12 & & \multirow{2}{*}{$\begin{array}{l}\text { Friction Clamp with } \\
16 \mathrm{ft} . \mathrm{lb} \text { Bolt Torque }\end{array}$} & Slow & 90 & 5 \\
\hline TC-2-13 & & & Slow & 90 & 5 \\
\hline
\end{tabular}

A strongback wall fixture with a hydraulic actuator was used to conduct 4-point bending testing. A set of custom-built 4-point bending support fixtures was used to align and load the test assemblies. A photograph of the 4-point bending test setup is shown in Figure 7. The 4-point bending tests were conducted in both low and high speed of $0.1 \mathrm{in} / \mathrm{min}(0.25 \mathrm{~cm} / \mathrm{min})$ and 0.5 $\mathrm{in} / \mathrm{min}(1.27 \mathrm{~cm} / \mathrm{min})$. Each bending test consists of loading the test assembly to approximately $14,500 \mathrm{lbf}(64.5 \mathrm{kN})$ with up to $\pm 1400 \mu \mathrm{in} / \mu \mathrm{in}$ strain at the middle of the test assembly. Similar to the tension/compression test procedure, the test assembly was held at peak load for up to 180 seconds to observe any measurement abnormalities. Each test was also repeated up to 10 test cycles to observe the repeatability of the measurements. The same data acquisition rates used in the tension/compression tests were also used in the bending test.

Table 4. FRICTION CLAMP 4-POINT BENDING TEST MATRIX

\begin{tabular}{|c|c|c|c|c|c|c|}
\hline $\begin{array}{c}\text { Test } \\
\text { Number }\end{array}$ & Test Articles & $\begin{array}{c}\text { Test } \\
\text { Configuration }\end{array}$ & $\begin{array}{c}\text { Test } \\
\text { Position } \\
\text { (Degree) }\end{array}$ & $\begin{array}{l}\text { Test } \\
\text { Speed }\end{array}$ & $\begin{array}{c}\text { Hold } \\
\text { Time } \\
\text { (seconds) }\end{array}$ & $\begin{array}{l}\text { No. of } \\
\text { Cycle }\end{array}$ \\
\hline B-1-1 & \multirow{11}{*}{$\begin{array}{c}8.625 " \text { OD } \times 0.148 " \\
\text { Wall } \times 120 " \text { Length } \\
\text { Pipe (Test Article \# } \\
7)\end{array}$} & \multirow{11}{*}{$\begin{array}{l}\text { Baseline (No } \\
\text { Clamp) }\end{array}$} & 0 & $\mathrm{~N} / \mathrm{A}$ & $\mathrm{N} / \mathrm{A}$ & 1 \\
\hline B-1-2 & & & 0 & High & 180 & 10 \\
\hline B-1-3 & & & 0 & High & 30 & 1 \\
\hline B-1-4 & & & 0 & High & 30 & 1 \\
\hline B-1-5 & & & 30 & High & 30 & 10 \\
\hline B-1-6 & & & 45 & High & 30 & 10 \\
\hline B-1-7 & & & 90 & High & 30 & 10 \\
\hline B-1-8 & & & 180 & High & 30 & 10 \\
\hline B-1-9 & & & 270 & High & 30 & 10 \\
\hline B-1-10 & & & 0 & Slow & 30 & 5 \\
\hline B-1-11 & & & 90 & Slow & 30 & 5 \\
\hline$\overline{B-2-1}$ & \multirow{15}{*}{$\begin{array}{c}8.625 " \text { OD } \times 0.148 " \\
\text { Wall } x 120 " \text { Length } \\
\text { Pipe (Test Article \# } \\
\text { 8) }\end{array}$} & \multirow{15}{*}{$\begin{array}{c}\text { Friction Clamp } \\
\text { (16 ft.lb Bolts } \\
\text { Torque) }\end{array}$} & 0 & High & 30 & 1 \\
\hline B-2-2 & & & 0 & High & 30 & 10 \\
\hline B-2-3 & & & 0 & High & 120 & 3 \\
\hline B-2-4 & & & 30 & High & 30 & 10 \\
\hline B-2-5 & & & 45 & High & 30 & 10 \\
\hline B-2-6 & & & 90 & High & 30 & 10 \\
\hline B-2-7 & & & 180 & High & 30 & 10 \\
\hline B-2-8 & & & 270 & High & 30 & 10 \\
\hline B-2-9 & & & 135 & High & 30 & 10 \\
\hline B-2-10 & & & 225 & High & 30 & 10 \\
\hline B-2-11 & & & 315 & High & 30 & 10 \\
\hline B-2-12 & & & 0 & Low & 30 & 5 \\
\hline B-2-13 & & & 90 & Low & 30 & 5 \\
\hline B-2-14 & & & 90 & High & 30 & 3.5 \\
\hline B-2-15 & & & 90 & Slow & 30 & 2 \\
\hline
\end{tabular}

Table 4 presents the 4 -point bending test matrix. The test matrix provides the test parameters, such as the amount of bolt torque applied, the test speed used, the amount of hold time for each test cycle, and the number of test cycles performed for each test. In order to compare the prototype fiber-optic measurements to the benchmark conventional resistance strain gauge measurements, a baseline test assembly was tested and used as benchmark reference. The resistance strain gauges on the baseline test assembly were located in the same locations as in the layout for the friction clamp test assembly. Tests were conducted at different rotational positions ranging from 0 degree to 315 degrees in order to vary the strain levels experienced by the different strain gauges. A magnetic strip with rotational

This material is declared a work of the U.S. Government and is not subject to copyright protection in the United States. Approved for public release; distribution is unlimited. 
degree markings was attached to the end of each test assembly to identify the corresponding rotational positioning.

\section{MARK I PROTOTYPE TEST RESULTS AND FINDINGS}

The strain measuring capability of the friction clamp prototype was evaluated by comparing the fiber-optic sensor strain measurements from the prototypes to the corresponding instrumented strain gauge measurements. The ratio, or percentage, of the sensor measurement to strain gauge measurement, referred to as performance ratio herein, was calculated to assess the strain sensing performance of the sensor. A sensor with $100 \%$ performance ratio will provide the same strain measurement reading as a resistance strain gauge attached directly to the test pipe surface. The friction clamp sensing performance data from all the tension/compression tests are presented in Table 5. The friction clamp sensing performance data from all of the 4-point bending tests are presented in Table 6. The maximum tensile strain sensing performance and maximum compressive strain sensing performance were calculated using the peak strain value from the most sensitive axial fiber-optic sensor in the test. The minimum tensile strain sensing performance and minimum compressive strain sensing performance were calculated using the peak strain value from the least sensitive axial fiber-optic sensor in the test. The red colored values in the table were calculated with the baseline test strain gauge data. The other data were calculated using values from strain gauges located adjacent to the clamp.

As shown in Tables 5 and 6, both the 4-inch and 8-inch friction clamp prototypes exhibited low sensing performance in all tests - tension, compression, and 4-point bending. The low performance can likely be attributed to the indirect coupling of the fiber-optic sensors to the test pipe, since the fiber-optic sensors were located on the exterior surface of the friction clamp body. As shown in Figure 8, increasing the bolt torque enhanced the coupling of the clamp and provided a slightly higher sensing performance. However, even at the highest torque level, the highest sensing performance ratio attained was around $50 \%$ of the compressive strain. For the tension/compression tests, the 8inch friction clamp exhibited much higher sensing performance than the 4-inch friction clamp. The sensing performance data presented in Figure 8 show that the prototype performed poorly in sensing tensile strain compared to sensing compressive strain. It is possible that the very slight contraction (necking) and expansion of the test pipe under tension and compression may have affected the coupling between the sensors and the pipe. The 8-inch friction clamp did not work well in the 4-point bending tests and exhibited relatively low sensing performance.
Table 5. FRICTION CLAMP FIBER-OPTIC SENSOR PERFORMANCE - TENSION/COMPRESSION TESTS

\begin{tabular}{|c|c|c|c|c|c|c|}
\hline $\begin{array}{l}\text { Test } \\
\text { Number }\end{array}$ & $\begin{array}{c}\text { Assembly Type / } \\
\text { Number }\end{array}$ & $\begin{array}{c}\text { Bolt Torque (ft- } \\
\text { lbff) }\end{array}$ & $\begin{array}{c}\text { Number of } \\
\text { Test Cycles }\end{array}$ & $\begin{array}{l}\text { Number of } \\
\text { Accumulative } \\
\text { Test Cycles }\end{array}$ & $\begin{array}{c}\text { Maximum Tensile } \\
\text { Strain Sensing } \\
\text { Resolution }(\%)\end{array}$ & $\begin{array}{c}\text { Maximum } \\
\text { Compressive } \\
\text { Strain Sensing } \\
\text { Resolution (\%) }\end{array}$ \\
\hline TC-2-1 & \multirow{6}{*}{$\begin{array}{c}\text { 4" Friction Clamp / } \\
\# 2\end{array}$} & 5 & 1 & 1 & $\mathrm{~N} / \mathrm{A}$ & $\mathrm{N} / \mathrm{A}$ \\
\hline TC-2-2 & & 5 & 1 & 2 & $\mathrm{~N} / \mathrm{A}$ & N/A \\
\hline TC-2-3 & & 5 & 10 & 12 & 3.4 & 6.7 \\
\hline TC-2-4 & & 5 & 10 & 22 & 3.9 & 7.4 \\
\hline TC-2-5 & & 7 & 3 & 25 & 9.1 & 7.9 \\
\hline TC-2-6 & & 10 & 5 & 30 & 13.9 & 14.9 \\
\hline TC-2-7 & \multirow{7}{*}{$\begin{array}{c}\text { 8" Friction Clamp / } \\
\# 5 a\end{array}$} & 10 & 1 & 1 & $\mathrm{~N} / \mathrm{A}$ & $\mathrm{N} / \mathrm{A}$ \\
\hline TC-2-8 & & 10 & 5 & 6 & 14.1 & 43.7 \\
\hline TC-2-9 & & 10 & 5 & 11 & 16.7 & 46.5 \\
\hline TC-2-10 & & 13 & 5 & 16 & 19.8 & 50.1 \\
\hline TC-2-11 & & 13 & 5 & 21 & 19.8 & 51.8 \\
\hline TC-2-12 & & 16 & 5 & 26 & 23.4 & 52.8 \\
\hline TC-2-13 & & 16 & 5 & 31 & 23.6 & 53.9 \\
\hline
\end{tabular}

Table 6. FRICTION CLAMP FIBER-OPTIC SENSOR PERFORMANCE - 4-POINT BENDING TESTS

\begin{tabular}{|c|c|c|c|c|c|}
\hline $\begin{array}{c}\text { Test } \\
\text { Number }\end{array}$ & $\begin{array}{c}\text { Rotational } \\
\text { Position (Degree) }\end{array}$ & $\begin{array}{c}\text { Number of Test } \\
\text { Cycles }\end{array}$ & $\begin{array}{c}\text { Number of } \\
\text { Accumulative } \\
\text { Test Cycles }\end{array}$ & $\begin{array}{c}\text { Maximum Tensile } \\
\text { Strain Sensing } \\
\text { Resolution (\%) }\end{array}$ & $\begin{array}{c}\text { Maximum } \\
\text { Compressive } \\
\text { Strain Sensing } \\
\text { Resolution (\%) }\end{array}$ \\
\hline B-2-1 & 0 & 1 & 1 & N/A & N/A \\
\hline B-2-2 & 0 & 10 & 11 & 20.9 & 13.4 \\
\hline B-2-3 & 0 & 3 & 14 & 25.5 & 18.3 \\
\hline B-2-4 & 30 & 10 & 24 & 12.2 & 19.2 \\
\hline B-2-5 & 45 & 10 & 34 & 19.8 & 21.5 \\
\hline B-2-6 & 90 & 10 & 44 & 12 & 13.9 \\
\hline B-2-7 & 180 & 10 & 54 & 5.2 & 14.9 \\
\hline B-2-8 & 270 & 10 & 64 & 4.8 & 8 \\
\hline B-2-9 & 135 & 10 & 74 & 3.4 & 15.1 \\
\hline B-2-10 & 225 & 10 & 84 & 14 & 26.7 \\
\hline B-2-11 & 315 & 10 & 94 & 8.9 & 4.7 \\
\hline
\end{tabular}

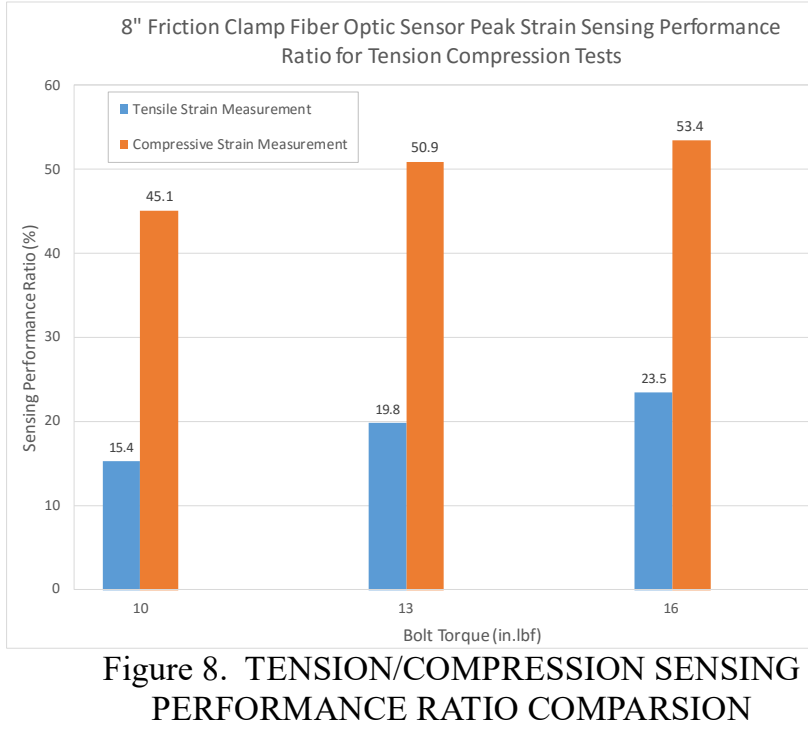

A typical strain vs. time plot of the fiber-optic sensor data and the corresponding resistance strain gauge data of tension/compression tests are shown in Figures 9 and 10. The strain measurements from the fiber-optic sensors have similar responses compared to the resistance strain gauge measurements, but the responses are at a much lower magnitude. The fiber-optic sensor strain measurements were consistent from the first to the last cycle during the tension/compression tests. However, the measurements were not as consistent in the 4-point

This material is declared a work of the U.S. Government and is not subject to copyright protection in the United States. Approved for public release; distribution is unlimited. 
bending test. Data dropouts and reduction of strain magnitude were observed as the number of test cycles increased. The inconsistencies observed during the bending test suggest that the sensor coupling may have been compromised.

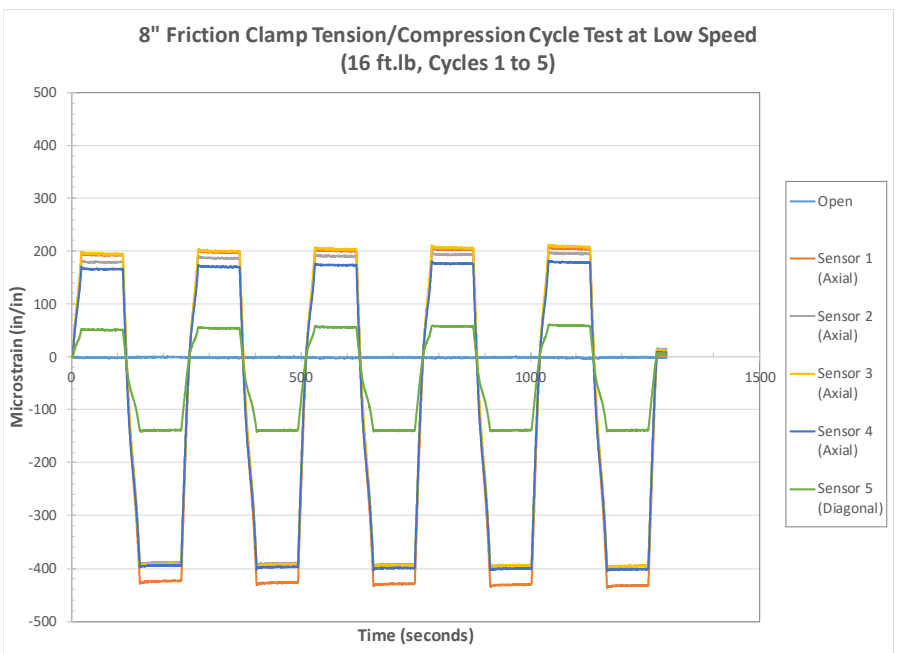

Figure 9. 8-INCH FRICTION TEST ASSEMBLY FIBEROPTIC SENSOR DATA FOR TENSION/COMPRESSION TEST \# TC-2-10

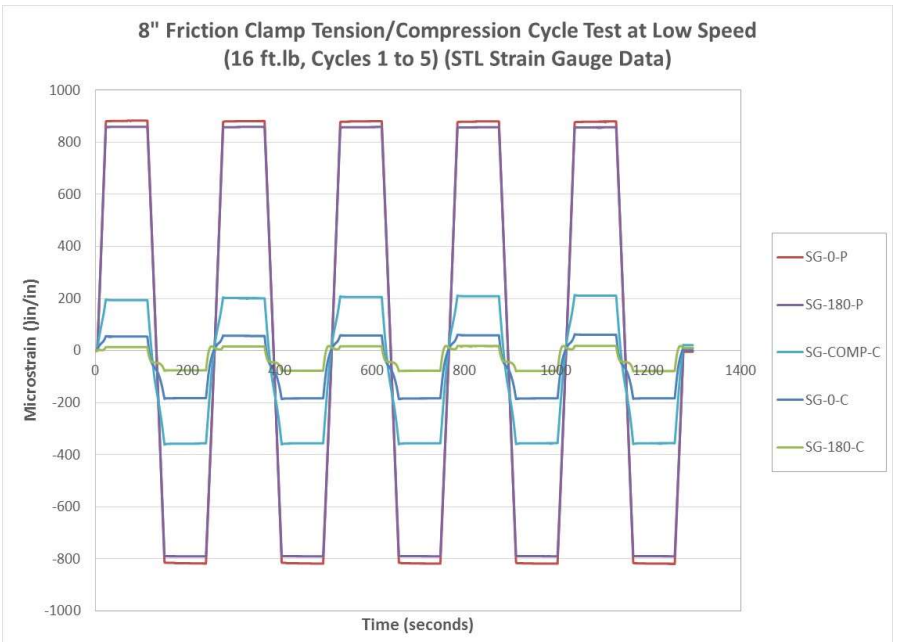

Figure 10. 8-INCH FRICTION TEST ASSEMBLY RESISTANCE STRAIN GAUGE DATA FOR TENSION/COMPRESSION TEST \# TC-2-10

The following is a summary of what was learned from the Mark I friction clamp prototype testing:

- The carbide friction coating appears to be quite effective in keeping the friction clamp firmly attached to the pipe surface. No slippage was observed during testing.

- The friction clamp sensing resolution increases with increased bolt torque. However, even at the highest bolt torque evaluated in this study, the highest strain measuring performance ratio was still limited to around $50 \%$ of the benchmark value.

- The positioning of the fiber-optic sensors on the exterior surface of the friction clamp is not optimal, and it may reduce the sensing performance of the monitoring system.

- The friction clamp exhibited a significantly lower strain sensing performance when it was under tension during the tension/compression test. This observation suggests that the necking or contraction of the test pipe during tensile loading may have loosened the sensor coupling to the pipe.

- Sensor coupling to the pipe was significantly degraded during the bending tests when relatively large bending deflections were experienced. As the number of bending cycles increased, some of the sensor measurements decreased correspondingly.

\section{MARK II DESIGN REFINEMENTS}

The findings from the Mark I friction clamp prototype testing demonstrated that there are several weaknesses in the design that need to be addressed in order to improve performance as a viable sensing system. There are several technical challenges, but they can be overcome with redesign and refinement. The following is a list of design changes and improvements which were incorporated into the Mark II friction clamp design to address the Mark I design shortcomings:

- Redesign of the friction clamp shell and fiber-optic sensor attachment method to provide a more secure and direct coupling to the structure.

- The redesigned clamp shell has a shorter and more compliant profile that provides more uniform surface contact. The redesigned clamp shell geometry is also less susceptible to surface decoupling due to large bending deflection.

- Incorporation of a self-locking mechanism that provides constant clamping force to counteract the contraction of the structure under tensile load.

- Incorporation of additional fiber-optic sensors to provide redundancy and to improve overall system reliability.

\section{MARK II DESIGN PRELIMINARY EVALUATION}

A full-size 24-inch $(61 \mathrm{~cm})$ diameter Mark II prototype was built by ATI and tested. A photograph of the compression test setup is shown in Figure 11. At the time of this writing, the data from the Mark II friction clamp prototype testing has not been fully analyzed yet. However, preliminary results indicate that the fiber-optic sensor measurements were tracking very well with the reference strain gauge measurements. There are also fewer deviations between the tension and compression measurements, which suggests that the new design is maintaining a high level of coupling during the tension tests. Preliminary strain data from

This material is declared a work of the U.S. Government and is not subject to copyright protection in the United States. Approved for public release; distribution is unlimited. 
the Mark II prototype tension/compression tests are shown in Figure 12.

The Mark II friction clamp design appears to have resolved some of the technical shortcomings of the Mark I design. The continued development of the friction-based post-installable fiber-optic sensor system could yet provide a valuable health monitoring system that will significantly enhance the operational safety of offshore oil and gas operations.

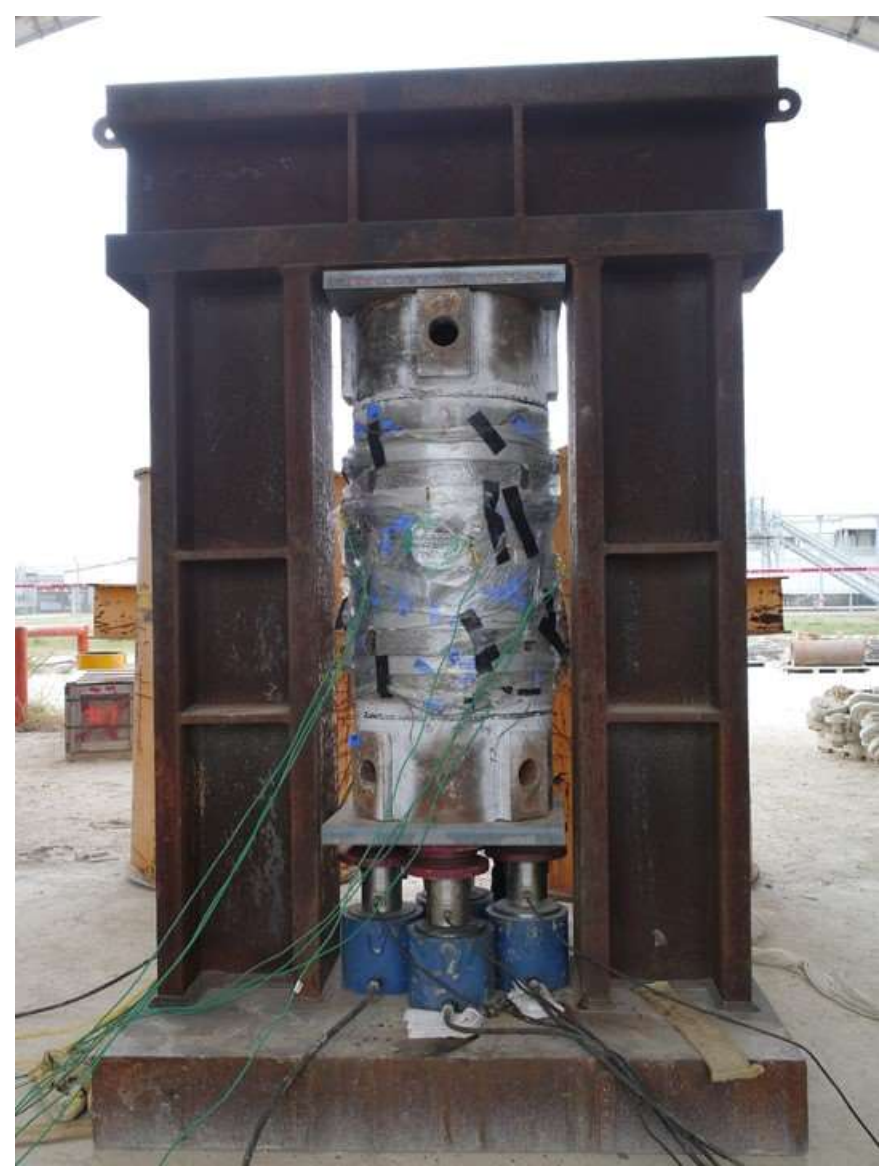

Figure 11. MARK II FRICTION CLAMP PROTOTYPE COMPRESSION TEST SETUP

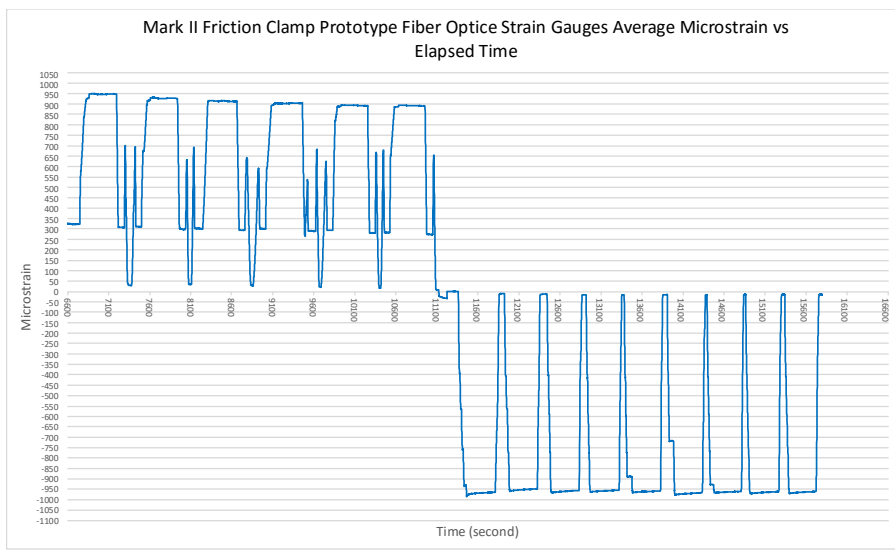

Figure 12. MARK II PROTOTYPE

TENSION/COMPRESSION TEST PRELIMINARY STRAIN DATA

\section{ACKNOWLEDGMENTS}

The authors wish to acknowledge Roman Hernandez, Daniel Brower, Conrad Wilson at ATI and Joseph Settles, Fernando Medina, Don Wilbanks, Ray Gonzalez, Larry Graham at NASA-JSC for their contributions to this study and the Space Act Agreement project.

\section{REFERENCES}

[1] Seaman, C., Brower, D., Le, S., Tang, H., 2015, "Development and Testing of a Post-Installable Deepwater Monitoring System Using Fiber-Optic Sensors", Proceedings of The $34^{\text {nd }}$ International Conference on Ocean, Offshore, and Arctic Engineering, St. John's Newfoundland, Canada May 31 - June 5.

[2] Brower, D., Brower, A., Hedengren, J., Shishivan, R. 2013, "New Advances in Post-Installed Subsea Monitoring Systems for Structural and Flow Assurance Evaluation", Proceedings of The $33^{\text {nd }}$ International Conference on Ocean, Offshore, and Arctic Engineering, San Francisco, California, USA, June 8-13.

[3] Fischer, B., Brower, D., 2010, "Fully Reimbursable Space Act Agreement Between Astro Technology Incorporated and NASA for Utilization of Environmental Test Facility", SAA-EA-10-004.

[4] Le, S., Orndoff, E., Tang, H., Tapia, A., 2011, "Final Report Testing of Subsea Pipeline Fiber Optic Monitoring System for Astro Technology Incorporated Annex 1 Space Act Agreement", CTSDINST-013. July

[5] Le, S., Tang, H., 2014, “ATI SAA Annex III Fiber Optic Sensor Clamp Prototypes Test Report”, CTSD-ADV-1172, December 12.

This material is declared a work of the U.S. Government and is not subject to copyright protection in the United States. Approved for public release; distribution is unlimited. 